\title{
Lobular Breast Carcinoma
}

National Cancer Institute

\section{Source}

National Cancer Institute. Lobular Breast Carcinoma. NCI Thesaurus. Code C3771.

An adenocarcinoma of the breast arising from the lobules. This is a relatively uncommon carcinoma, represents approximately $10 \%$ of the breast adenocarcinomas and is often bilateral or multifocal. 